UDC 347.1

LBC 67.404.219

\title{
ON THE LEGAL NATURE OF PLEDGE IN LIGHT OF THE CIVIL CODE REFORM OF THE RUSSIAN FEDERATION
}

\author{
Ruslan R. Emukhvari \\ Moscow Academy of Economics and Law, Moscow, Russian Federation
}

\begin{abstract}
Introduction: taking into account the analysis of the provisions of the current Civil Code of the Russian Federation on pledge, the provisions of the Development Concept of the Legislation on Property Law, the author of the article investigates the legal nature of pledge. In the civil law doctrine the existing points of view on the legal nature of pledge of property can be divided into the following groups: some consider the lien as part of property law; others qualify pledge as the category of contractual rights; still others insist on the mixed nature of the right of pledge and give it the proprietary-contractual features. In pursuing this aim, the author examines the difficulties arising from the imperfection of the legal regulation of pledge in the current Russian legislation. With the help of the scientific methods, especially the methods of system analysis and the comparative law method, it is established that the doctrine and practice do not put an end to the dispute about the nature of pledge as a proprietary or contractual right. Results: there are highlighted the approaches to the consideration of proprietary, contractual or proprietary-contractual nature of pledge which exist in the civil law doctrine. The judicial practice is focused. It is indicated that pledge is not formally recognized as a proprietary right in the modern judicial practice; there are opposite viewpoints on the approximation of the legal regime of pledge rights, as well as other rights similar to proprietary ones (e.g., leasehold rights), and the legal regime of "classical" proprietary rights (right of ownership, rights of servitude, etc.). Conclusions: there was drawn the conclusion on the dual nature of the right under study. Pledge can only be defined as the proprietary and contractual institution, because it is impossible to clearly qualify it either as a proprietary or contractual right.
\end{abstract}

Key words: pledge, legal nature of pledge, proprietary right, contractual right, the Development Concept of the Legislation on Property Law.

УДК 347.1

ББК 67.404.219

\section{О ПРАВОВОЙ ПРИРОДЕ ЗАЛОГА ИМУЩЕСТВА В СВЕТЕ РЕФОРМИРОВАНИЯ ГК РФ}

\author{
Руслан Ревазиевич Эмухвари \\ Московская академия экономики и права, г. Москва, Российская Федерация
}

\begin{abstract}
Введение: в статье с учетом анализа норм действующего Гражданского кодекса Российской Федерации о залоге, положений Концепции развития законодательства о вещном праве исследована правовая природа залога. В цивилистической доктрине существующие точки зрения на правовую природу залога имущества можно условно разделить на следующие группы: одни рассматривают залоговое право как часть вещного права; другие относят залог к категории обязательственных прав; третьи настаивают на смешанной - природе права залога и наделяют его вещно-обязательственными чертами. С этой целью автор изучает 긍 трудности, возникающие в связи с несовершенством правового регулирования залога в действующем росс сийском законодательстве. С помощью методов научного познания, прежде всего методов системного анализа и сравнительно-правового метода, установлено, что доктрина и практика не ставят точку в споре о природе залога как вещного или обязательственного права. Результаты: освещаются существующие в цивилистической доктрине подходы к рассмотрению вещной, обязательственной или вещно-обязательственной природы залога. Уделяется внимание судебной практике. Указывается, что формально залог не признается (2) вещным правом, в сложившейся в современный период судебной практике встречаются противоположные
\end{abstract}


позиции по сближению правового режима залоговых, а также иных прав, похожих на вещные (например, права аренды), с правовым режимом «классических» вещных прав (правом собственности, сервитутными правами и т. д.). Выводы: сделано заключение о двойственной природе исследуемого права. Залог может быть сконструирован только как вещно-обязательственный институт, ибо однозначно отнести его к вещному или обязательственному праву невозможно.

Ключевые слова: залог, правовая природа залога, вещное право, обязательственное право, Концепция развития законодательства о вещном праве.

\section{Введение}

Залог имущества является одним из классических гражданско-правовых институтов, который берет свое начало в римском праве как одно из прав на чужие вещи (jura in re aliena).

Во все исторические периоды данный институт тщательно исследовался представителями отечественной юридической мысли, такими как Д.И. Мейер, В.И. Синайский, Г.Ф. Шершеневич, Е.В. Васьковский, А.С. Звоницкий, Л.А. Кассо и др. В настоящее время в свете происходящего реформирования гражданского законодательства усилился интерес к исследованию правовой природы залога имущества, по которой, несмотря на достаточно давнюю историю вопроса и обширную литературу, не утихают споры [9].

Необходимо отметить, что попытки определения правовой природы залога имущества находили отражение в отечественном законодательстве, однако, на наш взгляд, их трудно назвать последовательными, поскольку Гражданский кодекс РСФСР 1922 г. относил залог к категории вещных прав, в Гражданском кодексе РСФСР 1964 г. нормы, регулирующие данный институт, содержались в разделе «Обязательственное право». Правовое регулирование залога имущества по действующему ГК РФ также осуществляется на основе $\S 3$ главы 23 в разделе «Общая часть обязательственного права».

\section{Доктрина и практика определения природы залога}

В цивилистической доктрине существующие точки зрения на правовую природу залога имущества можно условно разделить на следующие группы: одни рассматривают залоговое право как часть вещного права; другие относят залог к категории обязательствен- ных прав; третьи настаивают на смешанной природе права залога и наделяют его вещнообязательственными чертами.

Так, Е.В. Васьковский определяет залог как «вещное право, дающее своему обладателю возможность исключительного удовлетворения из цены данной вещи в случае неисполнения собственником последней лежащего на нем обязательства» [5].

Аналогичного взгляда придерживается А.А. Вишневский, по мнению которого из всех способов обеспечения исполнения обязательств, перечисленных в ГК, только залог имущества носит вещно-правовой характер. При этом право залога заключено непосредственно в заложенной вещи (имуществе), а не в личности залогодателя, и не предполагает наличия лично-доверительных отношений между кредитором и должником/акцессорным должником [6].

Залог обладает вещно-правовым характером, по мнению Г.Ф. Шершеневича, «имея своим объектом вещь, он всюду следует за нею (droit de suite), независимо от права собственности на нее, которое может переходить от одного лица к другому». К особенностям залога, которые не позволяют относить его к категории вещных прав, ученый относит: несамостоятельный характер залога; невключение правомочий по владению и пользованию предметом залога; наделение залогодержателя особым правомочием в отношении заложенного имущества, использование которого может повлечь лишение залогодателя принадлежащего ему права собственности [16].

При определении залога как вещного права в юридической литературе традиционно подчеркиваются следующие обстоятельства. Во-первых, право залога следует за вещью и сохраняется в случаях правопреемства. Во-вторых, залогодержатель имеет преимущественное право удовлетворения требований за счет заложенного имущества 
перед остальными кредиторами залогодателя. Залогодержатель использует вещно-правовые способы защиты: может предъявить иск об истребовании заложенного имущества из незаконного владения всех лиц, в том числе залогодателя. В-третьих, вправе предъявить иск об устранении всяких нарушений его права, хотя бы и не связанных с лишением владения [8].

Примечательно, что многие авторы относят залог к вещно-правовым институтам только при выполнении определенных условий. Например, Е.А. Суханов отмечает это при условии, что его объектом является вещь, а не имущественное право [14]. В.А. Белов предлагает рассматривать в качестве вещного права залог, соединенный с владением залогодержателя [3].

3.А. Ахметьянова допускает, что отдельные виды залога могут иметь характеристики исключительно вещного обременения, но при наличии следующих признаков: свойство публичности (приобретается путем регистрации в реестре, наложений знака о залоге, передачи во владение залогодержателя или третьего лица либо иным образом, устанавливаемым законом), свойство следования, а также приоритетное удовлетворение требований залоговых кредиторов [2].

\section{Вещно-правовой характер залога в современной доктрине российского частного права}

Многие ученые относят к числу вещных прав только залог недвижимого имущества (ипотеку) [4]. Аналогичный подход нашел отражение в Концепции развития законодательства о вещном праве (Концепция развития гражданского законодательства Российской Федерации (одобрена Советом при Президенте РФ по кодификации и совершенствованию гражданского законодательства 7 октября 2009 г.). По мнению ее разработчиков, «в разделе вещных прав следует указать на залог (ипотеку) как ограничение соответствующих прав, установить основание их возникновения (закон, договор), определить еще несколько генеральных положений, регулирующих залог как вещное обременение и сделать отсылку к 33 главы 23 ГК РФ». При этом отмечается, что «ни залог движимости, ни залог недвижимости не могут быть сконструированы как сугубо вещные права. Основной задачей модернизации залогового права является придание отдельным видам залога характера вещного права, который должен быть связан с публичностью залогового права и выражаться в свойстве следования и приоритета залогового кредитора перед прочими кредиторами» (Концепция развития гражданского законодательства Российской Федерации (одобрена Советом при Президенте РФ по кодификации и совершенствованию гражданского законодательства 7 октября 2009 года).

Следует отметить, что, несмотря на то что формально залог не признается вещным правом, в сложившейся в современный период судебной практике встречаются противоположные позиции по сближению правового режима залоговых, а также иных прав, похожих на вещные (например, права аренды), с правовым режимом «классических» вещных прав (правом собственности, сервитутными правами и т. д.) $[11 ; 12]$.

Так, по одному из дел, рассмотренных Судебной коллегией по экономическим спорам Верховного Суда РФ, был заключен договор аренды земли сельхозназначения. Участок находился в общей долевой собственности и с согласия всех сособственников был сдан в аренду. Позже один из сособственников попросил выделить его долю в натуре. Долю выделили, присвоили новый кадастровый номер выделенному участку. После этого собственник, доля которого была выделена в натуре, зарегистрировал право уже на свою индивидуальную вещь. Арендатор полагал, что он арендует по-прежнему весь участок, обрабатывал его и платил за аренду сособственникам. Когда арендатор узнал, что по реестру арендует не весь участок, то обратился с иском о признании права аренды на весь земельный участок. Когда дошло до Судебной коллегии по экономическим спорам, последняя в своем решении фактически сформулировала принцип эластичности аренды. Она указала, что если имущество, находящееся в общей долевой собственности, было в аренде, а потом из него выделили часть, то аренда сохраняется на целую вещь, включая выделившуюся часть ${ }^{1}$. Если следовать логике суда, 
то можно сказать, что раздел земельного участка не прекращает и право залога, как и право собственности, так как они эластичны.

Однако по другому делу Судебная коллегия по гражданским делам Верховного суда РФ пошла по иному пути. По делу № А65$21616 / 2014$ в целях обеспечения кредита банку был предоставлен в залог земельный участок. Потом по подложным документам, в том числе по подложной доверенности от банка, залог был погашен. Земельный участок разделили и перепродали другим лицам. Узнав об этом, банк обратился с иском о признании за ним права на залог. Однако Судебная коллегия по гражданским делам Верховного Суда РФ отказала в иске банку, поскольку заложенный земельный участок перестал существовать как объект недвижимости в связи с объединением земельных участков ${ }^{2}$. Как нам представляется, хотя речь в споре идет не о собственности, а о залоге, алгоритм решения должен быть такой же. В этой связи представленная логика суда нарушает принцип эластичности залогового права.

Таким образом, по вопросу сближения правового режима залоговых и вещных прав Верховным Судом РФ высказаны противоположные позиции.

Ставятся под сомнение вещно-правовые признаки залога сторонниками его обязательственно-правовой природы. Так, Р.С. Бевзенко отмечает, что при залоге за вещью следует не право на вещь, а правомочие залогодержателя требовать продажи заложенного имущества с публичных торгов [9].

\section{Обязательственно-правовой характер залога}

Среди приверженцев обязательственноправовой природы залога имущества необходимо выделить К.Н. Анненкова, В.М. Хвостова, В.В. Витрянского и др. В частности, по мнению К.Н. Анненкова, за правом залога необходимо признать скорее личный, чем вещный характер, хотя и с некоторыми чертами последнего» [1].

В.М. Хвостов определил залог как «обязательственное право требования, при котором личность должника, обязанного уплатить заключающийся в залоге долг, опре- деляется держанием заложенной вещи, а заложенная вещь является тем объектом, который в той или иной форме отвечает за неуплату долга» [15].

В.В. Витрянский также рассматривает залог в качестве института обязательственного права и отмечает, что именно такой позиции придерживается законодатель, поскольку: 1) предметом залога в соответствии с ч. 1 ст. 336 ГК РФ могут выступать не только вещи, но и имущественные права, которые не имеют самостоятельного объекта и соответственно не обладают вещно-правовыми характеристиками; 2) право залога может быть установлено на вещь или имущественное право, которые залогодатель приобретет в будущем, таким образом, право собственности или иное вещное право на предмет залога еще не возникло; 3 ) признание обязательственно-правовой природы залога делает возможным замену предмета договора на иное равноценное имущество; 4) залогодержатель вправе передать свои права и обязанности по договору другому лицу с соблюдением правил о переходе прав кредитора другому лицу путем уступки права требования; 5) обращение взыскания на заложенное имущество предполагает его продажу с публичных торгов в соответствии с положениями ст. 350 ГК РФ, приобретение кредитором права собственности на предмет залога исключается [10].

В последнее время все чаще высказываются мнения о двойственной правовой природе залога, так как однозначно отнести его к категории вещных или обязательственных прав не представляется возможным. Так, по мнению Б.М. Гонгало, «имеется преувеличение роли обязательственного элемента в сравнении с вещным, как и наоборот отстаивание вещно-правовой природы залога, соединенное с отрицанием обязательственно-правового элемента, ведет к некоторой недосказанности, к незавершенности конструкции залогового права» [7].

3.А. Ахметьянова обращает внимание на то, что Концепция развития гражданского законодательства Российской Федерации не относит залог к числу институтов вещного права, но имеет сходный правовой режим [2].

Особой позиции по вопросу определения правовой природы залога имущества придер- 
живается И.И. Пустомолотов. Ученый полагает, что спор о принадлежности залога к категории вещных или же обязательственных прав не имеет практического значения, а разгадка сущности данных правоотношений кроется в обеспечительной функции права залога. Залог сочетает в себе как вещно-правовые, так и обязательственные характеристики, объединенные единой целью - восстановление положения кредитора при неисполнении или ненадлежащем исполнении обязательства, следовательно, данный институт необходимо рассматривать с позиции всего обеспечительного комплекса. «Истинная природа залога заключается в признании его формой удовлетворения интереса кредитора за счет должника, то есть гражданско-правовой ответственностью» [13]. Такой подход не только отражает обеспечительную сущность данного средства, но и позволяет решить ряд проблем, возникающих в процессе правоприменения. В подтверждение своей позиции ученый указывает на формулировку ст. 334 ГК РФ, в соответствии с которой кредитор в силу залога имеет право получить удовлетворение из стоимости заложенного имущества.

\section{Выводы}

В целом не умаляя достоверности отдельных доводов сторонников вещного и обязательственного подходов к определению правовой природы залога, в качестве вывода отметим, что, по нашему мнению, в соответствии с целями разработчиков Концепции развития законодательства о вещном праве необходимо признавать его двойственную правовую природу. Залог может быть сконструирован только как вещно-обязательственный институт, ибо однозначно отнести его к вещному или обязательственному праву невозможно.

\section{ПРИМЕЧАНИЯ}

${ }^{1}$ Определение Верховного Суда РФ от 17 нояб. 2015 г. № 306-КГ15-8301 по делу № А6521616/2014. - Доступ из информ.-правового портала «Гарант».

${ }_{2}^{2}$ Определение Верховного Суда РФ от 10 нояб. 2015 г. № 80-КГ15-18. - Доступ из информ.правового портала «Гарант».

\section{СПИСОК ЛИТЕРАТУРЫ}

1. Анненков, К. Н. Система русского гражданского права. Т. ІІІ : Права обязательственные / К. Н. Анненков. - Спб. : Тип. М.М. Стасюлевича, 1901. - 491 с.

2. Ахметьянова, 3. А. О правовой природе залога / 3. А. Ахметьянова // Актуальные проблемы экономики и права. -2010 . - № 3. - С. 138-144.

3. Белов, В. А. Гражданское право. Особенная часть/В. А. Белов. - М. : Центр ЮрИнфоР, 2004. - 767 с.

4. Богатырев, Ф. О. Пределы прав залогодателя как собственника при залоге с оставлением у него заложенного имущества / Ф. О. Богатырев // Журнал российского права. - 2000. - № 3. - С. 108-120.

5. Васьковский, Е. В. Учебник гражданского права / Е. В. Васьковский. - М. : Статут, 2003. - 382 с.

6. Вишневский, А. А. Залоговое право / А. А. Вишневский. - М. : БЕК, 1995. - 179 с.

7. Гонгало, Б. М. Учение об обеспечении обязательств. Вопросы теории и практики / Б. М. Гонгало. - М. : Статут, 2004. - 222 с.

8. Гражданский кодекс Российской Федерации. Постатейный комментарий к разделу III «Общая часть обязательного права» / под ред. Л. В. Санниковой. - М. : Статут, 2016. - 662 c.

9. Гражданское право: актуальные проблемы теории и практики / под ред. В. А. Белова. - М. : Юрайт-Издат, 2007. - 993 с.

10. Договорное право. Книга первая: Общие положения / М. И. Брагинский, В. В. Витрянский. М. : Статут, 2011. $-847 \mathrm{c}$.

11. Жилищное право / под ред. П. М. Филиппова, А. О. Иншаковой, А. И. Гончарова. - М. : Юриспруденция, 2016. -528 с.

12. Практикум по дисциплинам гражданско-правовой специализации / И. В. Балтутите [и др.] ; под общ. ред. А. О. Иншаковой. - М. : Юрайт, 2017. - 440 с.

13. Пустомолотов, И. И. Правовая природа залога как средства обеспечения обязательств / И. И. Пустомолотов // Известия Тульского государственного университета. Серия «Экономические и юридические науки». - 2013. - № 1-2. - С. 86-90.

14. Суханов, Е. А. Лекции о праве собственности / Е. А. Суханов. - М. : Юристъ, 1999. - 384 с.

15. Хвостов, В. М. Система римского права, часть II «Вещное право» / В. М. Хвостов. - М. : Университетская тип., 1904. - 487 с.

16. Шершеневич, Г. Ф. Учебник русского гражданского права / Г. Ф. Шершеневич. - М. : Статут, 1995. $-461 \mathrm{c}$.

\section{REFERENCES}

1. Annenkov K.N. Sistema russkogo grazhdanskogo prava. T. III : Prava obyazatelstvennye 
[The System of Russian Civil Law. Vol. III: Obligation Rights]. Saint Petersburg, Tip. M.M. Stasyulevicha, $1901.491 \mathrm{p}$.

2. Akhmetyanova Z.A. O pravovoy prirode zaloga [About the Legal Nature of Deposit]. Aktualnye problemy ekonomiki i prava, 2010, no. 3, pp. 138-144.

3. Belov V.A. Grazhdanskoe pravo. Osobennaya chast [Civil Law. The Special Part]. Moscow, Tsentr YurInfoR Publ., 2004. 767 p.

4. Bogatyrev F.O. Predely prav zalogodatelya kak sobstvennika pri zaloge s ostavleniem u nego zalozhennogo imushchestva [Limiting the Rights of a Mortgager as Owner in Case of Making Deposit on the Condition of Appropriation by Them of the Mortgaged Property]. Zhurnal rossiyskogo prava, 2000, no. 3, pp. 108-120.

5. Vaskovskiy E.V. Uchebnik grazhdanskogo prava [Textbook of Civil Law]. Moscow, Statut Publ., $2003.382 \mathrm{p}$.

6. Vishnevskiy A.A. Zalogovoe pravo [Pledge Law]. Moscow, BEK Publ., 1995. 179 p.

7. Gongalo B.M. Uchenie ob obespechenii obyazatelstv. Voprosy teorii i praktiki [The Doctrine on Securing Obligations. Questions of Theory and Practice]. Moscow, Statut Publ., 2004. 222 p.

8. Sannikova L.V., ed. Grazhdanskiy kodeks Rossiyskoy Federatsii. Postateynyy kommentariy $k$ razdelu III «Obshchaya chast obyazatelnogo prava» [Civil Code of the Russian Federation. A Commentary to Section III "The General Part of the Obligation Law"]. Moscow, Statut Publ., 2016. 662 p.
9. Belov V.A., ed. Grazhdanskoe pravo: aktualnye problemy teorii i praktiki [Civil Law: Current Problems of Theory and Practice]. Moscow, Yurayt-Izdat Publ., 2007. 993 p.

10. Braginskiy M.I., Vitryanskiy V.V. Dogovornoe pravo. Kniga pervaya: Obshchie polozheniya [Contract Law. Book One: General Provisions]. Moscow, Statut Publ., 2011. 847 p.

11. Filippov P.M., Inshakova A.O., Goncharov A.I., eds. Zhilishchnoe pravo [Housing law]. Moscow, Yurisprudentsiya Publ., 2016. 528 p.

12. Baltutite I.V. Praktikum po distsiplinam grazhdansko-pravovoy spetsializatsii [Workshop in Civil Law Disciplines]. Moscow, Yurayt Publ., 2017. $440 \mathrm{p}$.

13. Pustomolotov I.I. Pravovaya priroda zaloga kak sredstva obespecheniya obyazatelstv [The Legal Nature of Deposit as a Means of Meeting Obligations]. Izvestiya Tulskogo gosudarstvennogo universiteta. Seriya «Ekonomicheskie i yuridicheskie nauki», 2013, no. 1-2, pp. 86-90.

14. Sukhanov E.A. Lektsii o prave sobstvennosti [Lectures on the Right of Property]. Moscow, Yurist Publ., 1999. 384 p.

15. Khvostov V.M. Sistema rimskogo prava, chast II «Veshchnoe pravo» [System of Roman Law, Part II "Property Law"]. Moscow, Universitetskaya tip., 1904. 487 p.

16. Shershenevich G.F. Uchebnik russkogo grazhdanskogo prava [Textbook of Russian Civil Law]. Moscow, Statut Publ., 1995. 461 p.

\section{Information about the Author}

Ruslan R. Emukhvari, Degree-Seeking Student, Department of Civil Law Disciplines, Moscow Academy of Economics and Law, Court Session Secretary, Arbitration Court of the City of Moscow, Varshavskoe shosse, 23, 117105 Moscow, Russian Federation, emukhvarirr@ya.ru.

\section{Информация об авторе}

Руслан Ревазиевич Эмухвари, соискатель кафедры гражданско-правовых дисциплин, Московская академия экономики и права, секретарь судебного заседания, Арбитражный суд г. Москвы, Варшавское шоссе, 23, 117105 г. Москва, Российская Федерация, emukhvarirr@ya.ru. 